\title{
CLINICAL NURSING STUDENTS' SELF CONFIDENCE DURING E-LEARNING IMPLEMENTATION
}

\author{
Made Satya Nugraha Gautama ${ }^{1}$, Sugiarsih' ${ }^{2}$, Totok Harjanto ${ }^{3 *}$ \\ ${ }^{1}$ Bachelor Student, School of Nursing, Faculty of Medicine, Public Health and Nursing, Universitas Gadjah Mada, Yogyakarta - \\ INDONESIA \\ ${ }^{2}$ Universitas Gadjah Mada Academic Hospital, Yogyakarta - INDONESIA \\ ${ }^{3}$ School of Nursing, Faculty of Medicine, Public Health and Nursing, Universitas Gadjah Mada, Yogyakarta - INDONESIA
}

Submitted: 20 September 2019; Final Revision from Author: 23 June 2020; Accepted: 29 June 2020

\section{ABSTRACT}

Background: Elearning as a learning method with a flexible and interactive pedagogical approach has a positive impact on the value of self-confidence of nursing students. School of Nursing, Faculty of Medicine Public Health and Nursing Universitas Gadjah Mada (FMPHN UGM) develop e-learning for nursing students in clinical practice learning which requires an evaluation to e-learning implementation by describing the self-confidence of the nursing student after use e-learning. The purpose of this study was to describe self-confidence (SC) of the clinical nursing students based on 3 selfconfidence's components that consist of cognitive, affective, and psychomotor.

Methods: A Descriptive study with a cross-sectional design toward 95 clinical nursing students in the stage of nursing management and basic nursing practice in September 2018 period at the School of Nursing FMPHN UGM. Data analysis used the univariate analysis with descriptive statistic test to describe respondent characteristic and variable. Student Satisfaction and Self-Confidence in Learning Instrument by National League for Nursing (NLN) in 2005 was used in this study. The instrument was through cultural adaptation and modification first.

Results: The self-confidence of nursing students as e-learning evaluation found that the majority of respondents (90,5\%) had high levels of self-confidence. Components of self-confidence, consist of cognitive, affective and psychomotor also showed that the majority of respondents were in the high category $(84,2 \% ; 88,4 \% ; 66,3 \%)$.

Conclusion: Clinical nursing students have high self-confidence after going through e-learning.

Keywords: Elearning, self-confidence, clinical practice learning

\section{ABSTRAK}

Latar belakang: Elearning sebagai salah satu metode pembelajaran dengan pendekatan pedagogik yang fleksibel dan interaktif berdampak positif pada nilai self-confidence mahasiswa keperawatan. Program Studi Ilmu Keperawatan Fakultas Kedokteran Kesehatan Masyarakat dan Keperawatan (PSIK FK-KMK) telah melaksanakan pembelajaran e-learning pada mahasiswa profesi ners yang diharapkan mampu meningkatkan self-confidence mahasiswa selama pembelajaran klinik. Penelitian ini bertujuan untuk mengetahui tingkat selfconfidence mahasiswa profesi ners dan tingkat kognitif, afektif serta psikomotor setelah melalui pembelajaran e-learning.

Metode: Penelitian deskriptif dengan rancangan cross sectional yang dilakukan di PSIK FK-KMK UGM. Pengambilan responden secara total sampling, sebanyak 95 mahasiswa profesi ners stase manajemen dan

*corresponding author, contact: toharjanto506@ugm.ac.id 
praktek keperawatan dasar periode September 2018. Analisis data menggunakan analisis univariat dengan uji statistik deskriptif untuk mendeskripsikan karakteristik data responden dan variabel yang diteliti. Instrumen yang digunakan adalah Student Satisfication and Self-Confidence in Learning (SCLS) yang dikembangkan oleh Nursing Leagues for National (2008) melalui proses cultural adaptation dan modifikasi.

Hasil: Gambaran self-confidence mahasiswa profesi PSIK FK-KMK UGM pada implementasi pembelajaran e-learning didapatkan bahwa mayoritas responden (90,5\%) memiliki tingkat self-confidence tinggi. Komponen self-confidence yaitu komponen kognitif, afektif dan psikomotor juga menunjukkan mayoritas responden berada pada kategori tinggi $(84,2 \% ; 88,4 \% ; 66,3 \%)$.

Kesimpulan: Mahasiswa profesi ners memiliki self-confidence tinggi pada implementasi pembelajaran e-learning.

Kata kunci: E-learning, self-confidence, pembelajaran klinik

\section{PRACTICE POINTS}

- Elearning menjadi salah satu metode pembelajaran yang dapat digunakan di praktek profesi ners

- Penyediaan bahan ajar yang menarik dapat meningkatkan ketertarikan mahasiswa dalam mengakses e-learning.

- Self-confidence mahasiswa profesi ners diukur dari capaian kognitif, afektif dan psikomotor pada implementasi e-learning

- Mahasiswa profesi ners harus memiliki self-confidence dalam menjalankan pembelajaran klinik

\section{PENDAHULUAN}

Penggunaan e-learning sejak tahun 2014 untuk sektor pendidikan di perguruan tinggi diperkirakan mencapai 38\%.1 Sementara itu, pertumbuhan e-learning di Indonesia pada beberapa sektor cukup pesat khususnya sektor pendidikan. Beberapa tahun ini, e-learning menjadi bagian utama dalam arus pendidikan kedokteran. Penggunaan teknologi pendidikan mampu mendukung semua aspek pendidikan kedokteran, terintegrasi dalam bentuk virtual lingkungan belajar atau learning management system. $^{2}$

Perkembangan e-learning saat ini dapat dimanfaatkan sebagai pendukung dalam proses belajar mengajar di perguruan tinggi terutama di pendidikan keperawatan. ${ }^{3}$ Pemanfaatan elearning di pendidikan keperawatan seperti mengakses jurnal, artikel dan sumber ilmiah lainnya telah diintegrasikan ke dalam proses pembelajaran dan praktek keperawatan., ${ }^{4,5}$ Dengan mengembangkan media e-learning pada pembelajaran mahasiswa profesi ners akan menjadi tolak ukur dalam meningkatkan mutu pendidikan profesi ners. ${ }^{6}$ Penelitian dan pengembangan berkelanjutan sangat penting pada aspek implementasi e-learning, terutama di dunia keperawatan. ${ }^{3,7}$

Tuntutan pendidikan profesi ners mengharuskan mahasiswa harus bertransisi dari pembelajaran secara teoritis ke situasi nyata sehingga menjadi tantangan mahasiswa profesi ners menghadapi situasi klinik. ${ }^{8}$ Kondisi ini memerlukan beberapa aspek untuk ditingkatkan seperti motivasi, rasa tanggung jawab, pengalaman dan nilai self-confidence (kepercayaan diri) mahasiswa. ${ }^{9}$ Self-confidence merupakan komponen utama keberhasilan suatu kompetensi keperawatan. ${ }^{10}$ Namun, pada kenyataanya bahwa sebesar 90,5\% mahasiswa keperawatan tidak percaya diri menghadapi jenjang profesi dan manajemen perawatan pasien. ${ }^{11}$

Setiap individu mahasiswa memiliki tingkat selfconfidence yang berbeda dan dipengaruhi beberapa faktor seperti tingkat pengalaman, penguasaan kompetensi, tingkat kesulitan masalah, kepercayaan (trust), dan dukungan sistem pembelajaran., ${ }^{7,10,12}$ Beberapa penelitian di luar negeri mengungkapkan bahwa e-learning sebagai bagian dari sistem pembelajaran berbasis online berdampak positif pada self-confidence mahasiswa keperawatan. ${ }^{13-15}$ 
Namun, sampai saat ini di Indonesia masih belum ada penelitian yang berfokus terhadap dampak penggunaan e-learning pada self-confidence mahasiswa profesi ners sehingga mahasiswa profesi ners yang telah terpapar pembelajaran ini perlu dilakukan penelitian.

\section{METODE}

Penelitian ini merupakan penelitian deskriptif kuantitatif dengan rancangan penelitian crosssectional. Penelitian ini merupakan suatu penelitian yang bertujuan untuk mengetahui gambaran tentang karakteristik self-confidence mahasiswa profesi ners dalam pembelajaran e-learning. Penelitian ini dilakukan di PSIK FK-KMK UGM pada bulan September hingga Desember 2018. Penentuan sampel menggunakan teknik total sampling. Alasan mengambil total sampling karena jumlah populasi yang kurang dari 100 sehingga seluruh populasi dijadikan sampel penelitian. ${ }^{16}$ Penelitian ini melibatkan mahasiswa profesi ners sebanyak 95 orang yang telah menyelesaikan stase manajemen dan Praktek Keperawatan Dasar (PKD) di Tahun 2018.

Instrumen yang diadaptasi dari Student Satisfication and Self-Confidence in Learning (SCLS) diberikan gratis tanpa biaya dan izin langsung ke Nursing Nursing Leagues for National. ${ }^{17}$ Instrumen asli terdiri dari 13 item SCLS, dengan 8 item menggambarkan karakteristik self-confidence. Kemudian dari 8 item, peneliti mengembangkan menjadi 15 item serta mengelompokkan ke dalam 3 komponen selfconfidence yaitu kognitif, afektif dan psikomotor. ${ }^{18} 5$ item self-satisfication tidak digunakan oleh peneliti dengan pertimbangan tidak bagian dari tujuan penelitian.

Hasil uji validitas isi melalui pendekatan Aiken's V (content validity coefficient) dengan membandingkan $\mathrm{V}$ minimum $(>0,60)$ pada 15 item instrumen selfconfidence diperoleh mean $\mathrm{V}$ value instrumen selfconfidence adalah $0,86(\mathrm{~V}>0,60)$ sehingga dikatakan valid. Uji reliabilitas adalah indeks yang menunjukkan sejauh mana alat pengukur dapat dipercaya atau dapat diandalkan. ${ }^{19}$ Uji reliabilitas dikatakan handal jika memiliki nilai koefisien Cronbach Alpha $>0,70$ dengan tingkat kepercayaan 95\% $(0,05) \cdot{ }^{20}$ Peneliti melakukan uji reliabilitas instrumen kepada 40 mahasiswa profesi ners tahun 2017 yang telah terlibat e-learning. Uji reliabilitas memperoleh nilai Cronbach Alpha 0,782. Berdasarkan hasil tersebut, instrumen self-confidence dikatan reliable.

Kategorisasi tingkat kepercayaan diri mahasiswa profesi ners didapatkan dari Formula Sturges melalui penghitungan interval skor tiap komponen dan skor total. Hasil perhitungan mendapatkan intepretasi dengan mengelompokkan hasil skor tiap komponen ke dalam empat kategori, yaitu rendah, sedang, tinggi dan sangat tinggi. Kategorisasi ini menggunakan empat interval yang telah ditentukan berdasarkan kebutuhan. $^{21}$

Data penelitian diolah menggunakan uji statistik deskriptif pada aplikasi SPSS versi 24 dan Microsoft Excel 2013 versi Windows 64 bit. Hasil analisis berupa tabel frekuensi dengan menampilkan persentase hasil data. Kumpulan data tersebut berubah menjadi informasi yang berguna dengan tujuan untuk mendeskripsikan hasil.

Penelitian ini telah mendapatkan izin dari Institution Research Board (Medical and Health Research Ethics Committe (MHREC) Faculty of Medicine, Public Health and Nursing Universitas Gadjah Mada - DR. Sardjito General Hospital dengan no KE/FK/0783/EC/2018.

\section{HASIL DAN PEMBAHASAN}

\section{Demografi}

Responden penelitian ini berjumlah 95 orang dengan proporsi mahasiswa profesi ners perempuan paling banyak yaitu 85 orang $(89,47 \%)$ dan hanya $10,53 \%$ adalah mahasiswa profesi ners laki-laki. Jumlah yang tidak proporsional ini merupakan kondisi yang umum terjadi di pendidikan keperawatan. Hal ini karena adanya konsep gender yang masih melekat di masyarakat tentang profesi keperawatan sebagai pekerjaan yang cocok untuk perempuan. . $22,23^{23}$

Berdasarkan frekuensi penggunaan, mayoritas mahasiswa profesi ners PSIK FK- KMK UGM $(82,11 \%)$ terbilang kadang - kadang $(2-3 \mathrm{x} /$ minggu $)$ dalam mengakses e- learning. Hanya beberapa mahasiswa saja $(2,11 \%)$ yang mengakses e-learning 
sering $(>3 \mathrm{x} /$ minggu). Hal ini berhubungan konten yang disajikan tidak setiap saat diperbarui serta sudah tersedianya bahan materi fisik, sehingga rata - rata mahasiswa mengakses e-learning setiap minggu guna memperoleh informasi kurikulum dan materi tambahan saja. ${ }^{24}$

Pada durasi mengakses, mayoritas mahasiswa mengakses e-learning kurang dari 30 menit (53,68\%). Sejalan dengan penelitian lain, bahwa mayoritas responden (57\%) mengakses kurang dari 30 menit. Sebab, masa aksesnya hanya digunakan untuk menjalankan tugas yang diberikan oleh dosen seperti upload tugas, download bahan ajar dan instruksi lainnya. ${ }^{25}$
Melihat gambaran frekuensi dan durasi diatas, strategi dalam meningkatkan keterlibatan mahasiswa dalam pembelajaran e-learning bisa dengan diskusi kasus secara online dan difasilitasi sebuah permainan pada konten pembelajaran. ${ }^{26}$

\section{Gambaran self-confidence mahasiswa profesi ners}

Hasil penelitian (Tabel 1) ini menunjukkan mayoritas mahasiswa profesi ners $(90,5 \%)(M=53,98 ; S D=4,08)$ berada pada kategori self-confidence tinggi pada pembelajaran e-learning praktek profesi ners PSIK FKKMK UGM.

Tabel 1. Distribusi frekuensi tingkat self-confidence pada mahasiswa profesi ners $(\mathbf{n}=95)$

\begin{tabular}{lccccc}
\multicolumn{1}{c}{ Kategori } & Skor & M & SD & F & $\%$ \\
Rendah & $15-30$ & - & - & 0 & 0 \\
Sedang & $31-45$ & 43,43 & 1,27 & 7 & 7,4 \\
Tinggi & $46-60$ & 53,98 & 4,08 & 86 & 90,5 \\
Sangat Tinggi & $61-75$ & 61,50 & 0,71 & 2 & 2,1 \\
\hline TOTAL & & & & 95 & 100 \\
\hline
\end{tabular}

Keterangan: M: rata -rata skor per kategori; SD: standar deviasi; f: frekuensi; \%: Persentase skor. (Sumber: Data Primer Tahun 2018)

Sejalan dengan penelitian Cobbet \& Clarke $^{14}$ menyatakan bahwa pembelajaran virtual atau e-learning sebagai salah satu metode komplementer dapat mempertahankan self-confidence mahasiswa keperawatan dalam menghadapi situasi klinik. Penelitian lain menyebutkan ${ }^{15}$ bawasannya program e-learning dapat meningkatkan skor kepercayaan diri (level of confidence) dari mean 3,55 (SD=1,14) menjadi mean 4,44 $(\mathrm{SD}=0,85)$. Hasil tersebut diperoleh dengan cara penyampaian materi dan video simulasi secara interaktif dan fleksibel.

Fleksibilitas e-learning sebagai sebuah massive open online course, tersedia dalam jaringan internet yang memungkinkan mahasiswa mengakses dimanapun tanpa batasan waktu. ${ }^{3}$ Keunggulan ini dimanfaatkan mahasiswa profesi ners dengan mengakses e-learning melalui smartphone masing-masing, yang berdampak positif terhadap pengetahuan, sikap dan self-confidence mahasiswa keperawatan menjalani pengalaman kliniknya. ${ }^{27}$

\section{Gambaran komponen kognitif}

Hasil pengukuran (Tabel 2) komponen kognitif mahasiswa ners ditemukan bahwa mayoritas mahasiswa profesi ners $(84,2 \%)$ memiliki nilai kognitif dengan kategori tinggi $(\mathrm{M}=18,24 ; \mathrm{SD}=1,44)$ dalam pembelajaran e-learning. 
Tabel 2. Distribusi frekuensi tingkat kognitif pada mahasiswa profesi ners $(n=95)$

\begin{tabular}{lccccc}
\multicolumn{1}{c}{ Kategori } & Skor & M & SD & F & $\%$ \\
Rendah & $5-10$ & - & - & 0 & 0 \\
Sedang & $11-15$ & 14,90 & 0,32 & 10 & 10,5 \\
Tinggi & $16-20$ & 18,24 & 1,44 & 80 & 84,2 \\
Sangat Tinggi & $21-25$ & 21,40 & 0,55 & 5 & 5,3 \\
\hline TOTAL & & & 95 & 100 \\
\hline
\end{tabular}

Keterangan: M: rata -rata skor per kategori; SD: standar deviasi; f: frekuensi; \%: Persentase skor. (Sumber: Data Primer Tahun 2018)

Hasil ini (Tabel 2) sejalan dengan penelitian Lee 28 yang menyatakan bahwa tingkat kognitif mahasiswa keperawatan lebih tinggi pada pembelajaran e-learning dibandingkan metode konvensional walaupun perbedaannya tidak signifikan. Hal ini didukung karena keberhasilan penyampaian informasi (kurikulum pembelajaran, tugas, dan bahan ajar) dan konten yang menarik di media e-learning. ${ }^{29,} 30$

Sementara itu, variasi data (Tabel 2) dalam penelitian ini sebanyak 10,5\% mahasiswa berada pada kognitif kategori sedang $(M=14,90 ; S D=0,32)$. Selaras dengan hasil tersebut bahwa tingkat kognitif tidak signifikan berbeda dengan pembelajaran konvensional. ${ }^{30} \mathrm{Hal}$ ini karena penggunaan smartphone di praktek profesi dapat mendistraksi dan mengganggu pemberian perawatan pada pasien. ${ }^{31}$ Selain itu, pemahaman mahasiswa terhadap fitur - fitur yang terdapat di media e-learning masih kurang, ketiadaan jaringan internet yang mumpuni, dan penerapan skill yang terbatas sehingga sulit membuat keputusan tepat. ${ }^{32}$

Di satu sisi, domain kognitif ini cocok sebagai bahan pengkajian pembelajaran online. ${ }^{33}$ Dan melalui perpaduan e-learning dan traditional learning (blended learning) memungkinkan dapat mencapai tingkat pengetahuan, pemahaman dan pengaplikasian pembelajaran yang efektif sebagai bagian komponen kognitif. 30

Penelitian Songkram et $a^{34}$ menjelaskan bahwa diperlukan pengembangan sistem e-learning dalam meningkatkan kemampuan kognitif mahasiswa. Adapun sistem yang dimaksud mencakup input yang terdiri atas elemen peran dosen dan instruktur, lingkungan belajar, sumber pembelajaran, dan motivasi; proses yang terdiri atas alur instruksi dan applicative thinking (proses ini memadukan conventional learning dan e- learning guna mencapai sistem yang efektif); dan hasil yang meliputi keterampilan kognitif dan evaluasi pembelajaran. Sistem ini dapat diukur dan dicapai melalui penerapan metode pada e-learning meliputi; diskusi kelas (menyegarkan kuliah sebelumnya), catatan kelas, tutorials, informasi yang cukup melalui grafik, presentasi PowerPoint, streaming video, kuis mandiri, problem based learning, dan latihan soal/tugas disertai jawaban dari ahli. ${ }^{33,34}$

\section{Gambaran komponen afektif}

Hasil penelitian (Tabel 3) pada komponen afektif mahasiswa profesi ners menunjukkan 88,4\% mahasiswa profesi ners memiliki tingkat afektif yang tinggi $(M=18,56 ; S D=1,40)$ dan $8,4 \%$ nya berada di kategori sangat tinggi $(\mathrm{M}=21,25 ; \mathrm{SD}=0,46)$ dalam pembelajaran e-learning. Bahwa selama proses pembelajaran e-learning, berdampak terhadap peningkatan komponen afektif mahasiswa yang ditunjukkan melalui rasa ketertarikan, motivasi belajar, sikap dan nilai pembelajaran, penerimaan materi, kemampuan merespon dan penilaian. 
Tabel 3. Distribusi frekuensi komponen afektif mahasiswa profesi ners ( $\mathrm{n}=95)$

\begin{tabular}{lccccc}
\multicolumn{1}{c}{ Kategori } & Skor & M & SD & $f$ & $\%$ \\
Rendah & $5-10$ & 0 & 0 & 0 & 0 \\
Sedang & $11-15$ & 13,33 & 1,53 & 3 & 3,2 \\
Tinggi & $16-20$ & 18,56 & 1,40 & 84 & 88,4 \\
Sangat Tinggi & $21-25$ & 21,25 & 0,46 & 8 & 8,4 \\
\hline TOTAL & & & 95 & 100 \\
\hline
\end{tabular}

Keterangan: M: rata -rata skor per kategori; SD: standar deviasi; f: frekuensi; \%: Persentase skor. (Sumber: Data Primer Tahun 2018)

Capaian yang tinggi tersebut dapat ditingkatkan melalui penyediaan video simulasi, fleksibilitas akses materi dan konten e-learning, feedback tugas dan quiz, serta face to face course (tatap muka) yang berdampak positif pada komponen afektif dalam memenuhi unsur pembelajaran e-learning. 33,40

\section{Gambaran komponen psikomotor}

Hasil penelitian (Tabel 4) pada komponen psikomotor mahasiswa profesi ners menunjukkan sebanyak
66,3\% mahasiswa memiliki tingkat psikomotor yang tinggi $((M=17,92 ; S D=1,46)$. Hasil yang tinggi ini sejalan dengan penelitian Rouhollah ${ }^{36}$ menyatakan bahwa e-learning sebagai suplemen pembelajaran efektif memacu psikomotor mahasiswa dalam menyiapkan keterampilan kliniknya. Penelitian lain menyebutkan melalui kombinasi e-learning dan tatap muka lebih efektif mengembangkan psikomotor mahasiswa keperawatan menghadapi situasi klinik di rumah sakit. ${ }^{37,38}$

Tabel 4. Distribusi frekuensi komponen psikomotor mahasiswa profesi ners ( $n=95)$

\begin{tabular}{lccccc} 
Kategori & Skor & M & SD & f & $\%$ \\
Rendah & $5-10$ & 10 & - & 1 & 1,1 \\
Sedang & $11-15$ & 14,17 & 1,29 & 30 & 31,6 \\
Tinggi & $16-20$ & 17,92 & 1,46 & 63 & 66,3 \\
Sangat Tinggi & $21-25$ & 21,00 & - & 1 & 1,1 \\
\hline TOTAL & & & 95 & 100 \\
\hline
\end{tabular}

Keterangan: M: rata -rata skor per kategori; SD: standar deviasi; f: frekuensi; \%: Persentase skor. (Sumber: Data Primer Tahun 2018)

Sementara itu, variasi data lain (Tabel 4) ditunjukkan penelitian ini yaitu terdapat $1,1 \%$ mahasiswa berada pada kategori rendah, dan 31,6\% mahasiswa masih menunjukkan kategori psikomotor sedang $(\mathrm{M}=14,17$; $\mathrm{SD}=1,29)$.

Guna meningkatkan psikomotor yang masih rendah atau sedang, strategi primer yang dapat diterapkan adalah dengan pemberian simulasi berpresisi rendah ke tinggi melalui video demonstrasi, dan deskripsi teks secara online atau gambar simulasi di setiap sesi. ${ }^{30}$ Strategi melalui video simulasi berguna untuk merepresentasikan situasi klinik yang efektif untuk dipelajari. Strategi ini berkontribusi pada pengembangan kompetensi klinis dan mengatasi ketakutan mahasiswa keperawatan dalam menghadapi situasi di klinik. ${ }^{39}$ Mahasiswa keperawatan dapat melihat berulang kali video yang disajikan 
sehingga mendukung kebutuhan belajar mandiri mahasiswa. ${ }^{40}$ Pembelajaran melalui video simulasi online harus memenuhi standar dan dapat memberikan konten yang berkualitas tinggi, benar, terbaru dan sesuai evidence based. ${ }^{41,42}$

Pemanfaatan model pengajaran lain, seperti flipped classroom juga efektif meningkatkan kompetensi klinik mahasiswa keperawatan. Melalui keterlibatan mahasiswa mempelajari materi dan kasus yang disediakan secara online di rumah atau dimanapun sebelum kuliah, kemudian mendiskusikan dan memecahkan masalah bersama saat kelas berlangsung. ${ }^{43}$

\section{Keterbatasan penelitian}

Keterbatasan penelitian hanya berfokus pada evaluasi pelaksanaan e-learning, sehingga peneliti tidak melakukan intervensi yang berdampak pada selfconfidence mahasiswa keperawatan. Perlu diketahui, komponen kognitif, afektif, dan psikomotor sebagai aspek utama self-confidence mahasiswa keperawatan tidak hanya dipengaruhi oleh sistem pembelajaran yang didapat, tetapi ada faktor lain seperti motivasi, penguasaan kompetensi, pengalaman, dan kepercayaan (trust).

\section{KESIMPULAN}

Mayoritas responden memiliki tingkat self-confidence tinggi. Komponen self-confidence terdiri atas kognitif, afektif dan psikomotor yang mayoritas responden berada pada kategori tinggi.

\section{SARAN}

Saran yang dapat diberikan dari hasil penelitian dilihat komponen psikomotor yang cenderung rendah, yaitu dibutuhkan pengembangan metode pembelajaran blended learning (kombinasi pembelajaran online dan tatap muka) yang disertai video demonstrasi/simulasi sebagai representasi situasi klinik sehingga mendukung kesiapan kompetensi mahasiswa keperawatan menghadapi praktek klinik. Pengembangan model pengajaran flipped classroom juga efektif meningkatkan kompetensi klinik keperawatan. Kasus dan skill dipelajari sebelum kuliah yang disediakan secara online, kemudian dibahas bersama di kelas dengan dosen.
Selain itu, diperlukan peningkatan aktivitas penggunaan e-learning melalui penyediaan bahan ajar yang menarik seperti grafik, streaming video, kuis mandiri, problem based learning yang sesuai evidence based, serta disertai feedback dari dosen sehingga dapat meningkatkan ketertarikan dalam mengakses e-learning.

\section{DEKLARASI KEPENTINGAN}

Para penulis mendeklarasikan bahwa tidak terdapat konflik kepentingan apapun terkait studi pada naskah ini.

\section{KONTRIBUSI PENULIS}

Made S.N. Gautama - Peneliti utama, analisis data, desain dan penulis manuskrip

Sugiarsih - Pembimbing penulis selama analisis, desain dan terlibat pada penulisan manuskrip

Totok Harjanto - Pembimbing penulis selama analisis, desain, dan terlibat pada penulisan manuskrip

\section{DAFTAR PUSTAKA}

1. Valentina P. E-Learning Market Trends \& Forecast 2014-2016 Report. https://www. docebo.com. Dikunjungi pada tanggal 27 November 2018

2. Masters K, Ellaway R. e-Learning in medical education Guide 32 Part 2: Technology, management and design. Medical Teacher. 2008 Jan;30(5):474-89.doi: $10.1080 / 01421590802108349$

3. Harjanto T, Dimas S. Tantangan dan peluang pembelajaran dalam jaringan: studi kasus implementas elok (e-learning: open for knowledge sharing) pada mahasiswa profesi ners. Jurnal Keperawatan Respati. 2018. doi: $10.35842 / \mathrm{jkry} . v 5 \mathrm{i} 0.282$

4. Abdelaziz M, Samer Kamel S, Karam O, Abdelrahman A. Evaluation of E-learning program versus traditional lecture instruction for undergraduate nursing students in a faculty of nursing. Teaching and Learning in Nursing. 2011 Apr; 6(2):50-8. 
5. Harjanto T, Sumunar D, Kintan P. E-Learning Implementation on Clinical Rotation Nursing Education: a Case Report of Universitas Gadjah Mada. 2018 4th International Conference on Science and Technology (ICST). 2018; ( ): 1-5. doi: 10.1109/ICSTC.2018.8528612

6. McCutcheon K, Lohan M, Traynor M, Martin D. A systematic review evaluating the impact of online or blended learning vs. face-to-face learning of clinical skills in undergraduate nurse education. J Adv Nurs. 2015 Feb; 71(2):255-70.

7. Perry P. Concept Analysis: Confidence/Selfconfidence. Nursing Forum. 2011 Oct;46(4):218 30.doi: 10.1111/j.1744-6198.2011.00230.x

8. O'Connor AB. Clinical instruction and evaluation: a teaching resource. Burlington, MA: Jones \& Bartlett Learning; 2015.

9. Van der Riet P, Levett-Jones T, Courtney-Pratt H. Nursing students' perceptions of a collaborative clinical placement model: A qualitative descriptive study. Nurse Education in Practice. 2018 May; 30:42-7.

10. Porter J, Morphet J, Missen K, and Raymond A. Preparation for high-acuity clinical placement: confidence levels of final-year nursing students. AMEP. 2013 Apr;83.doi: 10.2147/amep.S42157

11. Panduragan SL, Abdullah N, Hassan H, Mat S. Level of Confidence among Nursing Students in the Clinical Setting. Procedia - Social and Behavioral Sciences. 2011; 18:404-7. doi: 10.1016/j.sbspro.2011.05.059

12. Sudardjo, Esti H. Kepercayaan diri dan kecemasan komunikasi interpersonal pada mahasiswa. Jurnal Psikologi. 2003; Vol. 30(2). doi: $10.22146 /$ jpsi.7025

13. Jeffries PR, Dreifuerst KT, Kardong-Edgren S, Hayden J. Faculty Development When Initiating Simulation Programs: Lessons Learned From the National Simulation Study. Journal of Nursing Regulation. 2015 Jan; 5(4):17-23.

14. Cobbett S, Snelgrove-Clarke E. Virtual versus face-to-face clinical simulation in relation to student knowledge, anxiety, and self-confidence in maternal-newborn nursing: A randomized controlled trial. Nurse Education Today. 2016 Oct; 45:179-84. doi:10.1016/j.nedt.2016.08.004

15. Coyne E, Frommolt V, Rands H, Kain V, Mitchell M. Simulation videos presented in a blended learning platform to improve Australian nursing students' knowledge of family assessment. Nurse Education Today. 2018 Jul; 66:96-102. doi:10.1016/j.nedt.2018.04.012

16. Sugiyono. Metode penelitian pendidikan: pendekatan kuantitatif, kualitatif dan $\mathrm{R} \& \mathrm{D}$. Alfabeta; 2008

17. National League for Nursing. The Student Satisfaction and Self- Confidence in Learning for nursing education research. Use of NLN Surveys and Research Instruments.2005

18. Oh P, Jeon KD, Koh MS. The effects of simulation-based learning using standardized patients in nursing students: A meta-analysis. Nurse Education Today. 2015 May;35(5):e6-e15. doi: 10.1016/j.nedt.2015.01.019

19. Notoatmodjo S. Metodologi penelitian kesehatan (Cetakan VI). Jakarta: Penerbit PT. Rineka Cipta; 2012

20. Tavakol M, Dennick R. Making sense of Cronbach's alpha. Int J Medical Education. 2011 Jun 27;2:53-5.doi: 10.5116/ijme.4dfb.8dfd

21. Gordon, Rachel A. Applied statistics for the social and health sciences. Routledge; 2012.

22. Choi GH, Kim HJ, Kim JH, Nam ES, Hyun HJ, Kang HW, et al. Male Nurses' Experiences of Being Rejected in Nursing Practice. J Korean Acad Soc Nurs Educ. 2018 Feb 28;24(1):16-28. doi: $10.5977 /$ jkasne.2018.24.1.16

23. Zhang $\mathrm{H}, \mathrm{Tu} \mathrm{J}$. The working experiences of male nurses in China: Implications for male nurse recruitment and retention. J Nurs Manag. 2020 Mar;28(2):441-9.doi: 10.1111/jonm.12950

24. Judd T, Elliott K. Selection and Use of Online Learning Resources by First-Year Medical Students: Cross-Sectional Study. JMIR Med Educ. 2017 Oct 2;3(2):e17.doi: 10.2196/ mededu. 7382

25. Utami, H-D; Hermawati Y. Ruang Baca Virtual (Rbv) dan Bahan Ajar (Ba) Digital sebagai Media 
Pembelajaran Jarak Jauh. Jurnal Pendidikan, 2018, 19.1: 21-30.

26. Yunyongying P. Gamification: Implications for Curricular Design. Journal of Graduate Medical Education. 2014 Sep;6(3):410-2.doi: 10.4300/ JGME-D-13-00406.1

27. Kim JH, Park H. Effects of Smartphone-Based Mobile Learning in Nursing Education: A Systematic Review and Meta-analysis. Asian Nursing Research. 2019 Feb;13(1):20-9.doi: 10.1016/j.anr.2019.01.005

28. Lee T, Lin F. The effectiveness of an e-learning program on pediatric medication safety for undergraduate students: A pretest-posttest intervention study. Nurse Education Today. 2013 Apr;33(4):378-83.doi: 10.1016/j. nedt.2013.01.023

29. Lahti M, Hätönen $H$, Välimäki M. Impact of e-learning on nurses' and student nurses knowledge, skills, and satisfaction: A systematic review and meta-analysis. International Journal of Nursing Studies. 2014 Jan;51(1):136-49.doi: 10.1016/j.ijnurstu.2012.12.017

30. Amouzeshi Z, Soltani N, Taheri N. The Effect of Offline E-Learning on Cognitive Learning (Levels of Knowledge, Comprehension, and Application) of Fluid and Electrolyte Imbalances Course among Nursing Students. Journal of Surgery and Trauma, 2016, 4.1: 2-6.

31. Cho S, Lee E. Distraction by smartphone use during clinical practice and opinions about smartphone restriction policies: A crosssectional descriptive study of nursing students. Nurse Education Today. 2016 May;40:128-33. doi: 10.1016/j.nedt.2016.02.021

32. Arkorful V, Abaidoo N. The role of e-learning, advantages and disadvantages of its adoption in higher education. International Journal of Instructional Technology and Distance Learning, 2015, 12.1: 29-42

33. Kasilingam $G$, Ramalingam M, Chinnavan E. Assessment of learning domains to improve student's learning in higher education. J Young Pharm. 2014 May 9;6(1):27-33.doi: 10.5530/ jyp.2014.1.5
34. Songkram N, Khlaisang J, Puthaseranee B, Likhitdamrongkiat M. E-learning System to Enhance Cognitive Skills for Learners in Higher Education. Procedia - Social and Behavioral Sciences. 2015 Feb;174:667-73.doi: 10.1016/j. sbspro.2015.01.599

35. Stoyanova S, Yovkov L.Educational Objectives in E-Learning. International Journal of Humanities Social Sciences and Education (IJHSSE), 2016; 12-18

36. Ashouri E, Sheikhaboumasoudi R, Bagheri $\mathrm{M}$, Hosseini S, Elahi N. Improving nursing students' learning outcomes in fundamentals of nursing course through combination of traditional and e-learning methods. Iranian J Nursing Midwifery Res. 2018;23(3):217.doi: 10.4103/ijnmr.IJNMR_79_17

37. Bloomfield J, Roberts J, While A. The effect of computer-assisted learning versus conventional teaching methods on the acquisition and retention of handwashing theory and skills in pre-qualification nursing students: A randomised controlled trial. International Journal of Nursing Studies. 2010 Mar;47(3):28794.doi: 10.1016/j.ijnurstu.2009.08.003

38. Rourke S. How does virtual reality simulation compare to simulated practice in the acquisition of clinical psychomotor skills for pre-registration student nurses? A systematic review. International Journal of Nursing Studies. 2020 Feb; 102:103466.doi: 10.1016/j. ijnurstu.2019.103466

39. Cardoso AF, Moreli L, Braga FT, Vasques CI, Santos CB, Carvalho EC. Effect of a video on developing skills in undergraduate nursing students for the management of totally implantable central venous access ports. Nurse Education Today. 2012 Aug;32(6):709-13.doi: 10.1016/j.nedt.2011.09.012

40. McAllister M, Levett-Jones $\mathrm{T}$, Downer $\mathrm{T}$, Harrison P, Harvey T, Reid-Searl K, et al. Snapshots of simulation: Creative strategies used by Australian educators to enhance simulation learning experiences for nursing students. Nurse 
Education in Practice. 2013 Nov;13(6):567-72. doi: 10.1016/j.nepr.2013.04.010

41. Duncan I, Yarwood-Ross L, Haigh C. YouTube as a source of clinical skills education. Nurse Education Today. 2013 Dec;33(12):1576-80.doi: 10.1016/j.nedt.2012.12.013

42. Mackavey C, Cron S. Innovative strategies: Increased engagement and synthesis in online advanced practice nursing education. Nurse Education Today. 2019 May;76:85-8.doi: 10.1016/j.nedt.2019.01.010
43. Xu P, Chen Y, Nie W, Wang Y, Song T, Li H, et al. The effectiveness of a flipped classroom on the development of Chinese nursing students' skill competence: A systematic review and meta-analysis. Nurse Education Today. 2019 Sep;80:67-77.doi: 10.1016/j.nedt.2019.06.005 